\title{
Establishment of production of special wheel and track technology for extreme natural-climate conditions of the Arctic
}

\author{
Alex S. Diakov ${ }^{1, *}$, and George O. Kotiev ${ }^{1}$ \\ ${ }^{1}$ Bauman Moscow State Technical University, Baumanskaya 2-ya, 5/1, Moscow, Russia, 105005
}

\begin{abstract}
The complex natural and climatic conditions of the Arctic Zone of the Russian Federation (AZ of the RF) make it necessary to put forward special requirements for all types of ground equipment used to solve transport problems in this region. At present, the increase in economic costs in the operation of machinery is primarily due to the mismatch of the design of the vehicles used in the climatic zone. A set of measures for land transport that allows to ensure the socio-economic development of the AZ RF.
\end{abstract}

The complex natural and climatic conditions of the AZ of the RF make it necessary to put forward special requirements for all types of ground equipment used to solve transport problems in this region. At present, the increase in economic costs in the operation of machinery is primarily due to the mismatch of the design of the vehicles used in the climatic zone.

It should be noted that along with the design problems, the road network of the AZ of the $\mathrm{RF}$ is very poorly developed. So, on the territory of 13,9 million square $\mathrm{km}(80 \%$ of the territory of the country), the total length of the public highway network is only 200 thousand $\mathrm{km}$, of which roads with hard cover - 81 thousand $\mathrm{km}$, ground 118 thousand $\mathrm{km}$ and «winter roads» 7 thousand $\mathrm{km}$. Roads with solid capital coverings, allowing a load on the axis of 10 tons, no more than 8,5 thousand $\mathrm{km}$.

These circumstances entail a significant increase in transportation costs in the region, which in turn cause:

- Increase in the cost of construction of industrial, power and transportation facilities;

- Increasing the cost of mining;

- the complication of the delivery of passengers and goods to remote settlements and objects of the national economy.

It is obvious that the introduction of new roads in the Arctic zone will lead to improved transport accessibility, and in the long run, to the creation of new jobs, which will be conditioned by the need for the development of an accompanying infrastructure. This is proved, in particular, by the increase of cargo flows in the Republic of Sakha (Yakutia) after the commissioning of new highways and "winter roads" against the background of a decrease in the volume of traffic by river transport caused by shallowing of rivers.

\footnotetext{
${ }^{*}$ Corresponding author: diakov57@list.ru
} 
At present, in the conditions of increasing the pace of development of the AZ of the RF, the problem of ensuring a minimum level of harmful impact on low-bearing soils, with which modern land vehicles with traditional propulsors cause significant environmental damage, is also very topical. It should be noted that there is no corresponding legislative framework in terms of certification, conducted research and development work in this direction, are not systemic in nature.

Carried out analysis of the conditions of use of vehicles (TS) in the AZ of the RF allowed to identify the following key problems in the creation of land transport:

- low temperatures lead to a change in the requirements for aggregates, systems and operating materials (for example, in the work of internal combustion engines, friction elements, rubber products, etc.);

- the total resistance to movement, which is increased in comparison with the usual operating conditions, leads to the fact that the internal combustion engine and transmission work constantly in the zone of increased loads, which is characterized by increased wear of the parts and a decrease in durability;for movement on support surfaces with low bearing capacity, the necessary condition is the reduction of pressure on the ground. To overcome the clefts and wormwood, a prerequisite is the provision of TC amphibian properties;

- to overcome large distances between settlements, the autonomy of the vehicle (up to 3 days) is also a prerequisite, which in turn implies an increase in the power reserve (determined by the economy of the power plant, the power transmission efficiency) and the increase in the power capacity of the vehicle. With long autonomous actions, one of the defining properties of the TS is also the reliability of all systems.

In this connection, a mass-produced equipment not adapted to the conditions of the AZ of the RF is required, but specially designed for use in these conditions all-terrain vehicles (VTS), maximally unified with serial production.

In the Russian Federation there is a scientific and technical backlog created in the 1960s and 1980s. These are the developments of the Federal State Unitary Enterprise «Central Scientific Research Automobile and Automotive Engines Institute» and universities.

Achievement of high performance in terms of environmental friendliness and energy efficiency of the VTS movement is possible due to the use of electromechanical transmissions and modern engine with electronic control systems.

The use of environmentally friendly-wheeled propellers on low-pressure tires or rubberreinforced tracks will allow the VTS to move on soils with a low bearing capacity without harmful impact on the soil and vegetation cover.

VTS should be equipped with special life support systems, including residential modules to achieve the required level of autonomy.

Federal State Unitary Enterprise «Central Scientific Research Automobile and Automotive Engines Institute» of the Ministry of Industry and Trade of the Russian Federation together with Bauman Moscow State Technical University and the Moscow Polytechnic of the Ministry of Education and Science of the Russian Federation conducted a survey of regional government agencies to identify the needs for land transport for the AZ of the RF.

The analysis of the received information from subjects of the Russian Federation entering into the Arctic Zone, has allowed an indirect method to define an approximate need for the $\mathrm{TS}$, suitable for operation in $\mathrm{AZ}$ of the RF.

For passenger transportation in the AZ RF, about 7000 units of VTS.

For freight traffic in the AZ RF, about 18000 units of VTS.

Thus, the total annual demand VTS for complete social and economic provision of freight and passenger traffic in the AZ of the RF is 25000 units.

The work carried out by the joint-stock company «Scientific and Research Institute of Motor Transport» of the Ministry of Transport of the Russian Federation established that the 
depreciation periods for vehicles in operation in the AZ of the RF should be reduced by a factor of 1,5 - 2 compared to the regions of other climatic zones.

At present, a significant number of VTS models are produced in Russia (altogether 116), of which 55 models (or 47,4\%) of the VTS class of load-carrying capacity up to 1 ton with a total output of up to 800 units, which can not fully meet the requirements for implementation transport tasks in the $\mathrm{AZ}$ of the RF.

It should be noted that in the production of VTS in Russia at the present time there are not involved large automobile and tractor enterprises (GAZ Group, PJSC KAMAZ, JSC BAZ, JSC Scientific Production Corporation Uralvagonzavod, Concern Tractor Plants), and market needs are met due to small manufacturers, focused on the use of units and aggregates of mass-produced equipment.

In the world, the recognized leaders in this field are specialized companies: Foremost (Canada) and Rolligon (USA), which produce models of military-technical cooperation with different carrying capacity and types of propellers (wheeled and caterpillar).

The available scientific and technical background, and the technology of creating VTS on the basis of commercially available wheeled vehicles of high cross-country capability, allow us to conclude that it is necessary to create a TS for AZ of the RF on the basis of branch enterprises. According to the developed technology more than 100 units were produced equipment on the basis of products of automobile plants AZ GAZ, PJSC KAMAZ and JSC Automobile Plant URAL, which successfully passed the pilot operation at the enterprises of PJSC Gazprom in the Russian Federation.

At present, work is underway to create a military technical cooperation for the Russian Federation with the support of the Ministry of Education and Science of the Russian Federation.

Thus, for the implementation of the state program of the Russian Federation «Socioeconomic development of the AZ of the RF for the period until 2020 and beyond», approved by Decree of the Government of the Russian Federation of April 21, 2014 No. 366, it is necessary to implement its transport component - the program «Development and production of high-efficiency land transport-technological machines and complexes for passenger, freight and cargo-and-passenger transportation, including machine components, are intended for use in extreme climatic conditions Arctic ensuring environmentally safe operation as emissions and for Effects on the supporting surface».

The solution of the complex of tasks for the development of «support zones» of the AZ of the RF and the most important infrastructure projects is impossible without the appropriate nomenclature of specialized ground-based transportation and technological machines for Arctic applications, including:

- wheeled vehicles on low-pressure tires (families of trucks with a carrying capacity from 2 to 12 tons), including road trains with active trailers with a payload capacity of up to 30 tons for the transport of heavy indivisible goods;

- caterpillar machines in one- and two-link design, including trailers, low ground pressure and carrying capacity from 4 to 40 tons.

All specialized ground vehicles must be equipped with high-tech components implemented in the following activities:

- creation of production of stepless electromechanical transmissions;

- creation of production of hybrid power plants and onboard information control systems;

- creation of production of low-pressure tires;

- creation of production of rubber reinforced caterpillar propellers using composite materials.

The creation of VTS on the basis of high-tech components will reduce the requirements for the state of «winter roads» while providing a given level of mobility, patency and energy efficiency, as well as extend the period of their operation. 
For operation on public roads, design solutions should be proposed and implemented that allow VTS to function in a transport dimension (for example, for wheeled vehicles this is possible through the use of articulated-joint frames, for caterpillars - the use of rubberreinforced tracks).

It is obvious that the creation of high-tech productions of VTS and their components is possible only on the basis of large industrial enterprises with the involvement of leading research centers and universities.

It is known that the reliability of products is laid in the design and maintained in the process of operation.

For the effective functioning of equipment and operation in accordance with the «technical state», it is necessary to create means for servicing, repairing and evacuating, including collapsible, easily transported structures and sites for performing maintenance, repair and disposal of specialized ground transportation and technological machines and complexes.

The organization of maintenance and repair of ground vehicles in the AZ of the RF is also possible on the basis of service centers of manufacturers VTS.

Considering the large number of VTS required and the wide range of works performed in the conditions of the AZ of the RF, the service centers should ensure the fulfillment of the entire volume of production and logistics work, as well as their information support in stationary conditions. At the same time, it is necessary to equip the centers with mobile technical means to solve maintenance and repair problems in the areas of direct operation.

The program for the development of the ground transportation system for AZ of the RF will require the implementation of a set of government support measures, the creation of a public-private partnership mechanism, the stimulation of production development and the maintenance of the life cycle of VTS. Only a combination of these measures can provide a balance between the long-term strategic interests of the state in the Arctic zone and the costs of their implementation.

An assessment of the expected effectiveness and effectiveness of the proposed solutions shows that the implementation of the program for the development of the land transport system of Arctic applications will allow:

- create favorable conditions for more effective implementation of national projects in the field of development and development of the AZ of the R;

- drastically reduce the negative impact on the ecological environment of the Arctic;

- to activate innovative activities and accelerate the commercialization of the results of scientific and technical activities in the field of creating VTS and their components.

The complex of designated ground transportation measures will provide the social and economic development of $\mathrm{AZ}$ of the RF.

It should be noted that the this work was carried out at the Bauman Moscow State Technical University, with financial support from the government represented by the Russian Ministry of Education under the project: \#14.577.21.0272. (Identification number: RFMEFI57717X0272).

\section{References}

1. Novikov V.V., Pozdeev A.V., Diakov A.S. Research and testing complex for analysis of vehicle suspension units, Procedia Engineering. 2015. Vol. 129. P. 465-470 (2015) DOI: $10.1016 /$ j.proeng.2015.12.153

2. Kotiev G.O., Padalkin B.V., Kartashov A.B., Dyakov A.S. Designs and development of Russian scientific schools in the field of cross-country ground vehicles building, ARPN Journal of Engineering and Applied Sciences, (2017). T.12. № 4. C 1064-1071. 
3. Kotiev G.O., Diakov A.S. 2016. Method of developing the navigation systems of high mobility unmanned ground vehicles, News of southern Federal University. Engineering science. T. 174(1): S. 186-197. 